\title{
El cuerpo entre la resistencia y la asimilación: Estrategias incorporadas e itinerario corporal de un latin king
}

\author{
The Body between Resistance and Assimilation: \\ Embodiment Strategies \\ and Bodily Itinerary of a Latin King
}

\author{
Laura Porzio \\ Institució Milà i Fontanals. CSIC. Barcelona
}

\section{RESUMEN}

El artículo se centra en el relato biográfico de King Manaba, que durante muchos años fue el Inca, es decir, el líder supremo de una de las tribus de los Latin Kings en Cataluña y en España. Mediante el recurso de su biografía, nos centraremos en la presentación social del cuerpo de Manaba y de los Latin Kings, a través de sus vestidos, adornos y tatuajes. Desde un punto de vista teórico y analítico, el cuerpo representa uno de los elementos centrales para la creación y difusión del imaginario de las llamadas "bandas latinas". El cuerpo puede ser un estigma y crear desigualdades y, al mismo tiempo, un espacio de vivencias, reflexión y resistencia en cuanto emblema. Finalmente, el artículo reflexiona sobre la tensión y paradójica relación entre prácticas de resistencias y de asimilación en las culturas juveniles.

Palabras claves: Embodiment, Vestido, Tatuaje, Biografía, Culturas juveniles, Migraciones

\section{SUMMARY}

This article focuses on the biographical account of King Manaba, who for many years was the Inca, the supreme leader of the Latin King tribes in Catalonia and Spain. Referring to his biography, I will focus on the social presentation of the bodies of Manaba and the Latin Kings, through their dress, adornments and tattoos. From a theoretical and analytical point of view, the body represents one of the main elements for the creation and diffusion of the imaginary of the so called "Latin gangs". The body can be a stigma and create inequalities and, at the same time, a place of experiences, reflexion and resistance as an emblem. At the end, the article reflects on the tension and paradoxical relationship between resistance and assimilation practices in youth culture.

Key words: Embodiment, Dress, Tattoo, Biography, Youth Culture, Migration 
El 28 de octubre de 2003 Ronny Tapias, un estudiante colombiano, fue asesinado al salir de un instituto de secundaria de Barcelona. Esta acción violenta introdujo mediáticamente en España el fenómeno calificado como de "bandas latinas" , fenómeno que nos presenta elementos novedosos por lo que se refiere a la perspectiva de estudio e intervención en el campo de la juventud. Desde el punto de vista de los procesos migratorios, se visibiliza que las y los jóvenes tienen un peso específico en los colectivos de migrantes y que en la misma juventud española existen grupos de adolescentes con necesidades concretas, debidas a sus orígenes familiares. Por lo tanto, estos cambios estructurales fundamentales que se representan, entre otros, mediante nuevas prácticas de socialización en los espacios públicos, se construyen desde un primer momento como prácticas desviadas, violentas y delictivas. Ser joven, latinoamericano y frecuentar los parques se vincula a un imaginario de violencia y criminalidad. Los acontecimientos conflictivos que a veces protagonizaban algunas chicas y algunos $\operatorname{chicos}^{2}$, sirvieron para visibilizar socialmente un colectivo entero que hasta aquel momento había pasado desapercibido. Los medios de comunicación contribuyeron a la creación de un imaginario y estereotipo social que aún hoy marca, identifica y estigmatiza a una gran parte de la juventud de origen latinoamericano (Recio y Cerbino 2006). Durante los años 2005-07 participé en tres investigaciones sobre este tema ${ }^{3}$, y la construcción mediática del fenómeno de las "bandas latinas" fue siempre un elemento importante a tener en cuenta. Durante el proceso de investigación, se creó una base de datos exhaustiva

${ }^{1}$ Tal como hicimos en otros contextos, opto por utilizar la definición de "banda latina" entre comillas para marcar mi distanciamiento del significado ya irremediablemente estigmatizado y vinculado a prácticas delictivas y violentas, hecho del que se hablará a lo largo del presente artículo. Agradezco a Begonya Enguix la lectura crítica del manuscrito, así como sus comentarios y sugerencias.

${ }^{2}$ Durante los años (2005-2010) en que participé en diferentes investigaciones sobre las y los jóvenes latinoamericanos, sobre las organizaciones juveniles de calle y sobre identidades y prácticas culturales en algunos espacios públicos del área metropolitana de Barcelona, el porcentaje de miembros efectivos y reales de estos grupos oscilaba entre un 4 y 5\% de población juvenil de origen latinoamericano (Feixa, Porzio y Recio 2006; Feixa, Giliberti, et al. 2008).

${ }^{3}$ Espacio Público y Nuevas formas de sociabilidad. Jóvenes de origen latinoamericano en Barcelona. IP: Carles Feixa. Proyecto JOVLAT. ¿Reyes y reinas latinos? Identidades culturales de los jóvenes de origen latinoamericano en España. IP: Carles Feixa (SEJ200509333-C02-02/SOCI) y Les Organitzacions Juvenils Llatinoamericanes a Catalunya. ARAI. Ajuts Recerca Aplicada Matèria d'Immigració. IP: Oriol Romaní (2006-ARAI-00030). Aparte de mi implicación en estas investigaciones, los Latin Kings \& Queens en Cataluña configuran uno de los estudios de caso de mi tesis doctoral (Porzio 2009). 
sobre las noticias y reportajes que iban apareciendo en la prensa durante aquellos años, y este esfuerzo en la mirada generó una notable atención al presentar los resultados (Recio y Cerbino 2006; Canelles 2008; Porzio y Giliberti 2009).

A la luz de todos estos discursos, se puede afirmar que uno de los elementos más importantes que se utilizaron para crear y difundir el imaginario social de las "bandas latinas" y de sus miembros como inmigrantes, violentos e inadaptados fue, y sigue siendo sin ninguna duda, el cuerpo y su representación. En un gran número de artículos que aparecieron en la prensa durante aquellos años, la presentación de los grupos se centraba siempre en criterios estéticos, como el de vestir con unos pantalones anchos y caídos, llevar camisetas de grupos de rap y decorar la cabeza con gorras y pañuelos. En este contexto, me refiero al cuerpo como un vehículo de expresión que vuelve visible lo que es invisible y exterior lo que es interior (Grosz 2005: 47-51), como aquel elemento que permite a las personas, tanto percibir el mundo y los objetos que lo componen, como interactuar e intercambiar experiencias con los demás (Merleau-Ponty 2000: 162-164). El cuerpo entendido como un espacio de vivencias, de reflexión y resistencia en cuanto a emblema, y al mismo tiempo como creador de desigualdades en cuanto a estigma (Goffman 1998). La presentación social del cuerpo de estas chicas y de estos chicos, se ha visto vinculada a prácticas delictivas y desviadas, y ha llegado a generar verdaderos fenómenos de pánico moral en la sociedad de acogida (Choen 1972; Canelles 2008).

Este artículo analiza todos estos procesos corporales de percepciones, interacciones y adscripciones identitarias, focalizando la atención en las prácticas de vestir, adornos y transformaciones permanentes. Mediante el análisis de estas prácticas corporales, se reflexiona sobre la constante tensión y paradójica relación entre procesos de resistencias y de asimilación en el marco de los Latin King \& Queen.

En el primer apartado se presenta la perspectiva teórica y los conceptos claves que guían la etnografía, para después ofrecer un breve estado de la cuestión sobre las principales líneas de investigación relacionadas con las gangs. En los dos apartados etnográficos del artículo recupero y reelaboro partes del itinerario corporal de un rey latino, King Manaba ${ }^{4}$, centrándome en los temas vinculados a la cultura juvenil rapera y a los latin kings desde la perspectiva de los símbolos y emblemas que marcan los cuerpos, como por ejemplo los tatuajes. La historia de vida de Manaba se puede interpretar como la metáfora individual de una historia social:

\footnotetext{
${ }^{4}$ Este itinerario corporal fue uno de los que trabajé en la etnografía de mi tesis doctoral.
} 
¿El relato biográfico explica una vida? Diremos más bien que explica una interacción social activa mediante el expediente de una vida y [...] que se puede llegar a leer e interpretar toda una sociedad a partir de una biografía (Ferrarotti 1997: 45).

En cuanto a los aspectos estrictamente metodológicos, el trabajo se basa en dos prácticas de investigación principales: el método etnográfico que me llevó a compartir con las chicas y los chicos muchas situaciones de sus vidas, tanto como reinas y reyes (reuniones del grupo, rituales, actividades lúdicas, actos relativos al proceso de constitución de asociación, etc.), como situaciones en ámbitos más íntimos y privados en sus casas, con sus familias, etc. En lo relacionado con las fuentes orales, trabajé principalmente con el método biográfico, realizando historias de vida ${ }^{5}$ y analizándolas como itinerarios corporales, a partir de la propuesta teórica y metodológica de la antropóloga Mari Luz Esteban $(2004,2008)^{6}$. Las acciones e interacciones sociales que las personas experimentan durante sus vidas, se entienden como prácticas corporales inscritas en sus itinerarios biográficos. Esteban presenta el cuerpo, que en mi caso es un cuerpo vestido y adornado, como el elemento central de análisis. Ello le permite reflexionar sobre procesos de resistencia y empoderamiento, pero también de asimilación, que generan cambios directamente en lo social (Esteban 2004: 54).

\section{DE LAS ESTÉTICAS A LA PRÁCTICA DE VESTIR LOS CUERPOS}

La imagen es uno de los ejes fundamentales a la hora de construir, presentar y re-presentar la identidad corporal, tanto subjetiva como colectiva de los miembros de una cultura u organización juvenil. Durante las últimas décadas, el cuerpo se ha visibilizado aún más como un "espacio" público, ya que vivimos en una sociedad donde la mayoría de fenómenos y prácticas se sitúan alrededor del mismo (Esteban 2004). Hay que tener presente que esta hipotética liberación cultural que parecen vivir nuestros cuerpos en los siglos XX y XXI es ficticia, ya que el control y la regulación de las relaciones entre individuo y sociedad se hace y se construye directamente como control y regulación de estos mismos (Foucault 1998). En el marco de mi trabajo, me refiero al cuerpo como representación que crea y expre-

\footnotetext{
${ }^{5}$ Aparte de las biografías de reinas, reyes y personas cercanas al grupo sin ser miembros efectivos, realicé diferentes entrevistas temáticas, tanto individuales como grupales.

${ }^{6}$ Mari Luz Esteban reformula el concepto de biografía corporal de Francisco Ferrándiz (1995) y el de itinerario asistencial de la antropología médica (Comelles 1998).
} 
sa prácticas corporales y emblemas identitarios, pero al mismo tiempo como un elemento sobre el cual cicatrizan los estigmas sociales. Me refiero al cuerpo como resultado de discursos emic y etic sobre él y desde él, teniendo finalmente en cuenta el cuerpo sentido y las emociones. Estos tres elementos: la representación corporal (Gatens 1996), los discursos (Foucault 1998) y el cuerpo sentido (Blackman 2008) interactúan constantemente en las experiencias individual y colectiva de las personas.

Las prácticas corporales experimentadas e in-corporadas ${ }^{7}$ (Csordas 1990, 2005) y por lo tanto actuadas, dotan de significado los itinerarios biográficos de cada persona, que se encuentran situados en contextos estructurales concretos. Los procesos de in-corporación de prácticas y símbolos en las biografías personales, son además fundamentales para determinar el habitus de cada persona y de su grupo social de referencia (Bourdieu 1977, 1983). El habitus consiste en un conjunto de normas, valores y esquemas clasificatorios a través de los cuales los individuos perciben, miran y entienden el mundo. Este sistema clasificatorio sirve también para situarse en un espacio social concreto y para dirigir las propias acciones. Las prácticas culturales y las ideas sobre el mundo son productos de este mismo aprendizaje cultural que orienta los esquemas clasificatorios de toda la sociedad. El habitus, que se adquiere durante la socialización primaria, no se aprende sino que se in-corpora. En otras palabras, es un entrenamiento corporal en normas, valores, prácticas y sistemas de distinción entre grupos y personas. Finalmente, es un buen sistema de control social y un mecanismo de supervivencia aplicado desde el sistema social vigente, siempre evidenciando la relación con el cuerpo, como saber in-corporado previo a la conciencia.

En todas las sociedades y las culturas las personas tienen cuerpo, o más bien, son cuerpo. Asimismo, los cuerpos visibles que se representan socialmente, en su gran mayoría son cuerpos vestidos. Un cuerpo vestido es un cuerpo adornado con prendas de ropa, con tatuajes, con otros tipos de ornamentos o simplemente con un perfume. Para la juventud en general y para las culturas juveniles en particular, adornar el cuerpo constituye una práctica identitaria y de localización social suficientemente determinante donde "la ubicua naturaleza del vestido parece apuntar al hecho de que la ropa y los adornos son uno de los medios a través de los cuales los cuerpos se vuelven sociales y adquieren sentido e identidad. El acto individual

\footnotetext{
7 Aún no existe un consenso entre las y los investigadores sobre cómo traducir el concepto de embodiment y, entre las diferentes posibilidades, utilizo el término incorporar, que desde mi punto de vista pone en evidencia el hecho de que hablamos de procesos continuos de ida y vuelta, donde intervienen diferentes factores.
} 
y muy personal de vestirse es un acto que prepara el cuerpo para el mundo social, hacerlo apropiado, aceptable, de hecho, hasta respetable e incluso deseable" (Entwistle 2002: 20).

Vestirse es una práctica que se aprende desde la infancia, tanto en lo referente a la técnica de ponerse la ropa (Mauss 1971), como en lo relacionado con el aprendizaje normativo sobre lo que nos tenemos que poner, cómo y en qué circunstancias. Según Joanne Entwistle (2002), la ropa es aquel elemento que crea una relación entre el cuerpo privado y el cuerpo público, ya que representa una experiencia íntima, y por lo tanto biográfica, y al mismo tiempo una experiencia pública como carta de presentación de cualquier individuo y de cualquier grupo. La práctica de vestirse crea y determina el contexto en el cual una persona desarrolla su propia experiencia corporal, y la performatividad de la acción de adornar el cuerpo se da de manera más visible y más extrema durante la adolescencia y la juventud. Las elecciones corporales de cualquier persona, mujer u hombre, alto o bajo, joven o viejo, siempre están influidas por el habitus in-corporado socialmente. Pero lo que diferencia la relación entre el cuerpo y la generación es su extrema visibilidad y, en algún caso, la conciencia del rol identitario que tienen las estéticas. Las situaciones formales y/o informales de la vida cotidiana se rigen por una serie de códigos, donde el vestir tiene un papel determinante. Cuando se infringen estos códigos, se desatienden las expectativas sociales, hecho que muy a menudo es imputado a las culturas juveniles. Aquellas prácticas corporales que las y los jóvenes viven y sienten como emblemas, se interpretan y se transforman en estigmas por los que los observan desde una perspectiva externa, como por ejemplo otros jóvenes que han elegido prácticas diferentes para sus cuerpos.

En este marco, es interesante recuperar las ideas de Entwistle (2002) que hacen hincapié en la relación entre individuo y contexto social, y que invitan a pensar en el cuerpo como el vínculo entre la práctica de vestirse y el fenómeno de la moda. La socióloga propone pensar en la moda como una práctica corporal que se basa en el acto de vestirse y donde el cuerpo, o la corporeidad, es el elemento que reproduce y describe, tanto los cambios y las evoluciones dentro de la moda, como las actitudes individuales hacia ella. A la luz de todo esto, me refiero a la estética y los símbolos corporales de las culturas juveniles como prácticas de vestir y adornar los cuerpos. Es decir, prácticas de transformación del cuerpo que inciden en el cuerpo individual y en el cuerpo social (Douglas 1998), y que determinan las biografías corporales de cada chica y chico como individuos, pero también como miembros de un grupo específico. La transformación del cuerpo, temporal o permanente, que llevan a cabo algunos jóvenes a nivel individual, si pensamos en los itinerarios biográficos de cada uno, y a nivel grupal, si 
nuestra mirada se centra en los emblemas identitarios colectivos, son prácticas representativas, pero también discursivas donde no sólo es importante aquello que se ve, sino que también es relevante aquello que se relata sobre la misma práctica. El concepto de "discurso" de Foucault (1998) es muy pertinente porque crea un enlace significativo entre cuerpo, símbolos corporales e interpretaciones. Los discursos que se generan a partir de esta relación repercuten sobre los pensamientos, pero todavía más sobre las acciones. Los discursos hechos desde la hegemonía (Gramsci 1975) sobre los cuerpos de nuestra sociedad crean ideas normativas acerca de cómo hay que pensar el cuerpo, como, por ejemplo, las de cuerpo saludable, atractivo y estéticamente agradable (Weitz 2001). El resultado de estas ideas es generar una serie de cuerpos domesticados y normalizados por parte de un biopoder que los vigila desde un punto de observación privilegiado que no puede ser visto por los observados.

Las ideas de Foucault sobre el poder, el cuerpo y el discurso son interesantes si pensamos en la sociedad de consumo y el uso que hace la clase política dominante. La moda, y los relativos criterios estéticos que difunde, es uno de los instrumentos que tiene el sistema de poder vigente para controlar los cuerpos contemporáneos, orientar su consumo cultural y volver dóciles sus conductas. El hecho de consumir, y de cómo se consume, implica posicionamientos relevantes que se quedan atrapados en el inconsciente de la mayoría de los consumidores (Featherstone 1991). Muy a menudo se piensa que los cuerpos, desnudos o vestidos, del siglo XXI sufren menos constricciones respecto a los siglos pasados, y que las mujeres y los hombres viven una corporalidad liberada. A pesar de esto, si reflexionamos sobre las expectativas que tiene que cumplir un cuerpo contemporáneo, llegamos a la conclusión de que seguimos sufriendo constricciones tanto visibles y tangibles como simbólicas y discursivas. Los códigos sobre los ornamentos corporales disciplinan los cuerpos y las conductas, y crean unos sujetos normalizados que manifiestan el consenso con los patrones culturales dominantes. Es decir, los cuerpos contemporáneos se modelan según una estética normativa que sirve de pasaporte para obtener la plena aceptación social y que produce cuerpos físicos, carnales y visibles, y: "most important, using the body as a political tool continues to place women's bodies at the center of women's identities" (Weitz 2001: 680). Esta reflexión acerca del cuerpo femenino se puede extrapolar y dirigir hacia la corporalidad expresiva y significante de las culturas juveniles. Las culturas juveniles se construyen sobre una tensión constante entre propuestas alternativas alrededor del consumo y de las adscripciones identitarias que se resisten a los discursos hegemónicos sobre la presentación social del cuerpo, y al mismo tiempo, en prácticas de consumo que normalizan los cuer- 
pos y que persiguen su asimilación y aceptación social (Thornton 1996). Mediante las experiencias biográficas de King Manaba y de su organización juvenil de calle, reflexionaremos sobre esta lucha de poderes entre cuerpos resistentes y/o asimilados y neutralizados. Pero ¿qué es una organización juvenil de calle?

\section{LA TODOPODEROSA NACIÓN DE LOS LATIN KINGS \& QUEENS: DE STREET GANG A STREET ORGANIZATION}

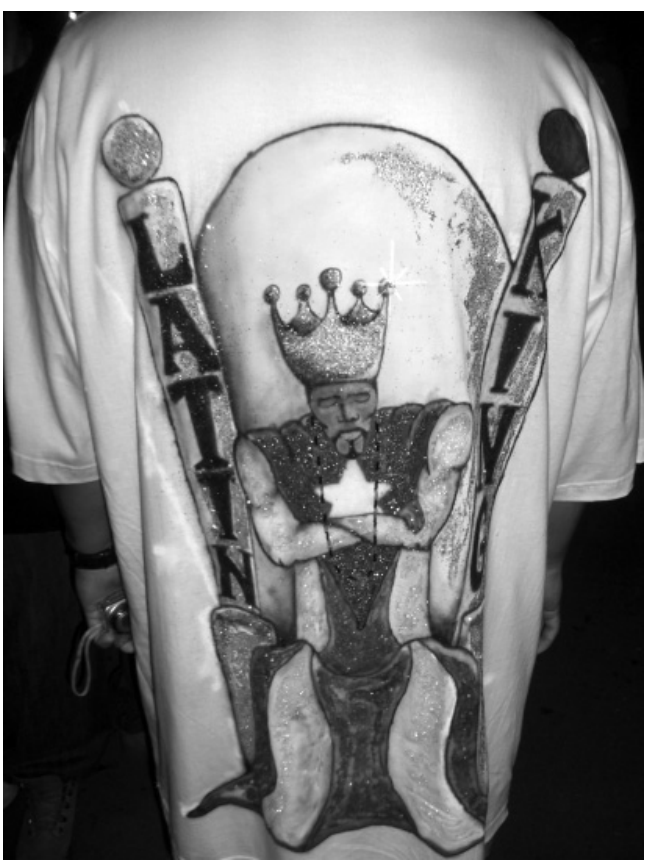

FIGURA 1.- - Rey Latino y camiseta serigrafiada. Dibujo propio. Foto de J. C. Martínez.

La Escuela de Chicago, que impulsó el nacimiento y desarrollo de la antropología urbana a partir de las primeras décadas del siglo XX, dedicó sus esfuerzos a descifrar el fenómeno de las street gangs en EE. UU. La idea principal a partir de la cual se guiaban estas investigaciones era que la sociedad tenía que ser reformada mediante la destrucción de las patologías que minaban su organización y perpetuación, y una de estas patologías eran las bandas juveniles. Uno de los primeros trabajos donde emergió la orientación normativa y, aunque de manera muy débil, el intento de sistematizar la observación empírica del objeto de estudio como posibilidad metodológica fue: The Gang. A

Study of 1313 gangs of Chicago de Frederick Trasher que investiga la relación de las bandas con la delincuencia (Trasher 1963 [1926]). En 1943, William Foote Whyte publica Street Corner Society que presenta una característica innovadora consistente en centrarse en el estudio de un grupo reducido, es decir, sustituyendo la mirada macro de sus predecesores por una investigación dedicada a dos grupos específicos. Estas aportaciones académicas orientan las primeras aproximaciones conceptuales a la idea de banda juvenil. Las gangs se desarrollan durante el crecimiento urbanístico de 
la sociedad norteamericana en el seno de comunidades como la afroamericana, o de origen migrante como la italiana y la hispana, y se pueden interpretar como intentos de recuperar los elementos que caracterizaban las identidades culturales y las prácticas de sus padres y de sus abuelos en los países de origen. En otras palabras, hablamos de procesos de recuperación mágica de la identidad étnica originaria por parte de las "segundas y terceras" generaciones de inmigrantes (Feixa, Porzio y Recio 2006). Esta corriente marca el desarrollo posterior de los estudios sobre las bandas en Norteamérica donde, aunque se tienen en cuenta formas de sociabilidad menos territoriales y homogéneas, se sigue estudiando a estos grupos desde una vertiente criminológica (Klein 1995; Klein et al. 2001; Hagedorn 2007). Los estudios sobre las gangs impulsan también el nacimiento de The Eurogang Project que se constituye como una red de investigadores europeos y norteamericanos que se dedican, cada uno en su contexto local, a estudiar grupos juveniles "violentos y delictivos". En esta red de trabajo, los investigadores intercambian conocimientos, generando modelos teóricos y metodológicos comparativos mediante la elaboración de proyectos de investigación internacionales, organización de congresos, seminarios y publicaciones conjuntas (Van Gemert, Peterson y Lien 2008). En líneas generales, se puede afirmar que este tipo de mirada analítica es la que predomina actualmente en la literatura internacional sobre las street gangs.

En los EE. UU también encontramos las aportaciones de investigadores que han analizado estos grupos desde una vertiente socio-política y cultural (Brotherton y Barrios 2004; Kontos, Brotherton y Barrios 2003). Luis Barrios y David Brotherton proponen el concepto de street organizations ${ }^{8}$ para desvincular estos grupos de su interpretación exclusivamente criminológica y para incidir en los objetivos sociales de las organizaciones, como por ejemplo cumplir funciones de ayuda mutua y canales de solidaridad entre sus miembros.

A group formed largely by youth and adults of marginalized social class which aims to provide its members with resistant identity, an opportunity to be individually and collectively empowered, a voice to speak back to and challenge the dominant culture, a refuge from the stresses and strains of barrio or ghetto life, and spiritual enclave within which its own sacred rituals can be generated and practiced (Brotherton y Barrios 2004: 23).

La Todopoderosa Nación de Reyes y Reinas Latinos nace en Chicago alrededor de los años 40, aunque no es hasta la década de los 70 cuando

\footnotetext{
${ }^{8}$ Organización juvenil de calle. Para desvincular mi trabajo de una visión criminológica y desviante opto por adoptar la nomenclatura propuesta por Brotherton y Barrios.
} 
empieza a adquirir la forma organizativa actual y a definir sus propósitos, entre los cuales están favorecer el progreso del conjunto de la comunidad latina y defender sus derechos violados por la sociedad blanca norte-americana con poder adquisitivo (Kontos 2003: 133-135.). Durante los años 80, y en la ciudad de Nueva York, la organización llega a tener las características y dimensiones actuales. Durante los años 90, y a causa de las deportaciones o regresos voluntarios desde Estados Unidos hacia América Latina, la Nación llega a Ecuador. A partir del 2000, los movimientos migratorios transnacionales hacia Europa introducen estas nuevas formas de sociabilidad juvenil en España, adaptando sus significados y prácticas a los nuevos contextos estructurales. Según Brotherthon y Barrios (2004) la Todopoderosa Nación de los Reyes y Reinas Latinos ${ }^{9}$ sería un movimiento de resistencia que crea una cosmovisión alternativa a la dominante y que lucha contra la subordinación que padece la comunidad hispana en EE. UU. Desde esta perspectiva, serían un verdadero movimiento social que, junto con otros que defienden los derechos de las minorías étnicas, crea sus prácticas culturales como modelos de resistencia a la discriminación y a la explotación a la que están sometidos como colectivos. Según el sociólogo italiano Luca Queirolo Palmas, que también comparte esta aproximación sociocultural al estudio de los grupos de calle, estos jóvenes construyen estas organizaciones en contextos migratorios ${ }^{10}$ para obviar la soledad que sufren como recién llegados y: "se inventan un espacio para conseguir afecto, solidaridad, identidad, dignidad y respeto" (Queirolo 2008: 114). Mauro Cerbino, antropólogo de la FLACSO de Quito y siguiendo la misma perspectiva de trabajo, pone énfasis en la marginalidad y la exclusión social que padecen los jóvenes con pocos recursos económicos en Ecuador, a quienes el Estado ha olvidado y abandonado (Cerbino y Barrios 2008). Según Cerbino, la Nación ${ }^{11}$ de los latin kings representa una comunidad imaginada que ofrece a sus miembros protección social y todo aquello que globalmente un Estado tendría que garantizar (Cerbino y Rodríguez 2008).

Muchos son los aspectos que resultan interesantes de todas estas perspectivas de análisis, como por ejemplo la propuesta conceptual de definir a las y los latin kings como una organización de calle, subrayando así unas diferencias importantes respecto al concepto de cultura juvenil, como un

\footnotetext{
9 Traducción castellana del nombre originario: Almighty Latin Kings E Queens Nation.

${ }^{10}$ Luca Queirolo Palmas ha realizado diferentes etnografías en Génova, Italia, con las y los latin kings u otras organizaciones juveniles como las y los Netas.

${ }^{11}$ Nombre émico de la organización. Más adelante se ofrecen elementos etnográficos específicos sobre el significado del término.
} 
sistema de comunicación y representación flexible y heterogéneo (Feixa 1998). Una organización juvenil de calle, en cambio, es un sistema más rígido, que implica recuperar los paradigmas subculturales que inciden en la clase social y el territorio para ser interpretado (Hall y Jefferson 1975). La elección del término organización remarca que estamos hablando de un sistema de códigos, símbolos y prácticas orgánicas y estructuradas que implican un proceso de institucionalización del poder. La Todopoderosa Nación de los latin kings \& queens tiene una estructura jerárquica y piramidal sobre la que se fundamentan todos los significados y las prácticas rituales y lúdicas del grupo. El recurso al término Nación nos remite a unos conceptos prácticos, pero también discursivos y retóricos, que van desde lo global, como grupo que existe en diferentes contextos nacionales ${ }^{12}$ y que aspira a unas conexiones transnacionales ${ }^{13}$, a lo local, es decir, a cada uno de los contextos concretos de los grupos. La Nación por lo tanto es la estructura más grande de la organización y comprende todas las tribus existentes en el mundo. Además, es la definición émica que utilizan las reinas y los reyes para referirse a su organización. A cada territorio estatal le corresponde una tribu ${ }^{14}$ o más, ya que pueden existir grupos enfrentados en cada ámbito territorial. Dentro de una tribu pueden existir sectores, como en el caso de España, los de Cataluña o de Madrid, y finalmente llegamos a la célula más pequeña de la organización que son los chapters o capítulos. Los capítulos corresponden a lo que se puede entender como el grupo base de socialización, donde las relaciones entre los miembros son cotidianas (Romaní, Porzio et al. 2009).

Toda esta estructura compleja se fundamenta a través de normas y objetivos que hay que aprender ${ }^{15}$ y cumplir para poder estar dentro del grupo. Los objetivos principales son el progreso, la protección y el respeto, que acercan la organización a otros grupos de ayuda mutua. Otro elemento que los caracteriza es la espiritualidad y todos los aspectos rituales vinculados a ella. Existen ritos de ascensión individual como el de coronación, de con-

\footnotetext{
${ }^{12}$ Europa, norte, centro y sur de América.

${ }^{13}$ Casi siempre más discursivas que reales.

${ }^{14}$ Sagrada Tribu Athaualpa Ecuador (Ecuador); Lions Tribe (Nueva York); STAS/Tribu American Spain, ALKQN-Spain, etc.

15 Existe toda una producción escrita denominada por ellos mismos "documentos", "escrituras" o "libros sagrados", "Biblia", que reconstruye la historia del grupo y que explica sus objetivos y su funcionamiento, tanto ritual como práctico. Cada rey y cada reina realiza un verdadero proceso de aprendizaje durante las fases previas a la coronación. Uno de los requisitos para ser coronadas/os es demostrar los conocimientos y, por lo tanto, la capacidad de renacer como un nuevo rey o una nueva reina.
} 
firmación de las parejas mediante el apulseramiento, de premio de méritos y otros ritos corales donde se vive y se expresan los significados colectivos del grupo mediante los rezos o la celebración de eventos y fechas importantes (Porzio 2009: 167-172). Según Luis Barrios (Brotherton y Barrios 2004; Barrios 2008) esta espiritualidad es una de las estrategias de resistencia que el grupo pone en marcha para luchar contra las desigualdades sociales que padecen en cuanto a jóvenes, pobres y de origen migrante. Las prácticas espirituales de la Nación serian una experiencia de empoderamiento dentro de los contextos transnacionales, es decir, el sistema espiritual tendría efectos y manifestaciones diferentes según los contextos y las estrategias necesarias para incidir en la transformación del sistema de opresión al cual las chicas y los chicos de las Naciones están sometidos (Barrios 2008).

Este sistema complejo se rige gracias a una estricta jerarquía de liderazgo. La misma idea de significados y prácticas que van de lo global a lo local (de la tribu a los capítulos) se vuelve a presentar por lo que hace a las coronas supremas, que es un consejo formado por el Inca, que sería el líder máximo, y el Cacique que es el brazo derecho del Inca y que lo sustituye en funciones cuando él no está. Después viene el Esforzador, que se ocuparía del tema de los conflictos, tanto internos, como con los otros grupos, el Tesorero que gestiona el dinero ${ }^{16}$ y finalmente el Secretario o Maestro que es el encargado de preservar la integridad de los libros sagrados y de transmitir su contenido a las y los que quieren entrar (Porzio 2009: 167). Para acabar esta introducción etnográfica hace falta mencionar ${ }^{17}$ que las reinas aparecieron como miembros efectivos en la tribu de Nueva York en los años 80 y que, a partir de este momento, formaron parte de las diferentes tribus nacionales, configurando a menudo capítulos propios como latin queen.

\section{PARA SER RAPERO HAY QUE SABER COMBINAR MÚSICA Y VESTIMENTA PARA REPRESENTARSE}

César, conocido como King Manaba, fue el Inca de la Todopoderosa Nación de los Reyes y Reinas Latinos en España. César, nació y creció en Ecuador en el seno de una familia obrera y humilde, aunque no en un con-

\footnotetext{
${ }^{16}$ Cada rey y cada reina paga una cuota que, en teoría, sirve para subvencionar las actividades lúdicas y rituales del grupo.

${ }^{17}$ Para una visión más profunda sobre el tema de las reinas y su rol dentro del grupo se pueden consultar los textos de Romaní, Porzio et al. (2009) y Porzio (2009).
} 


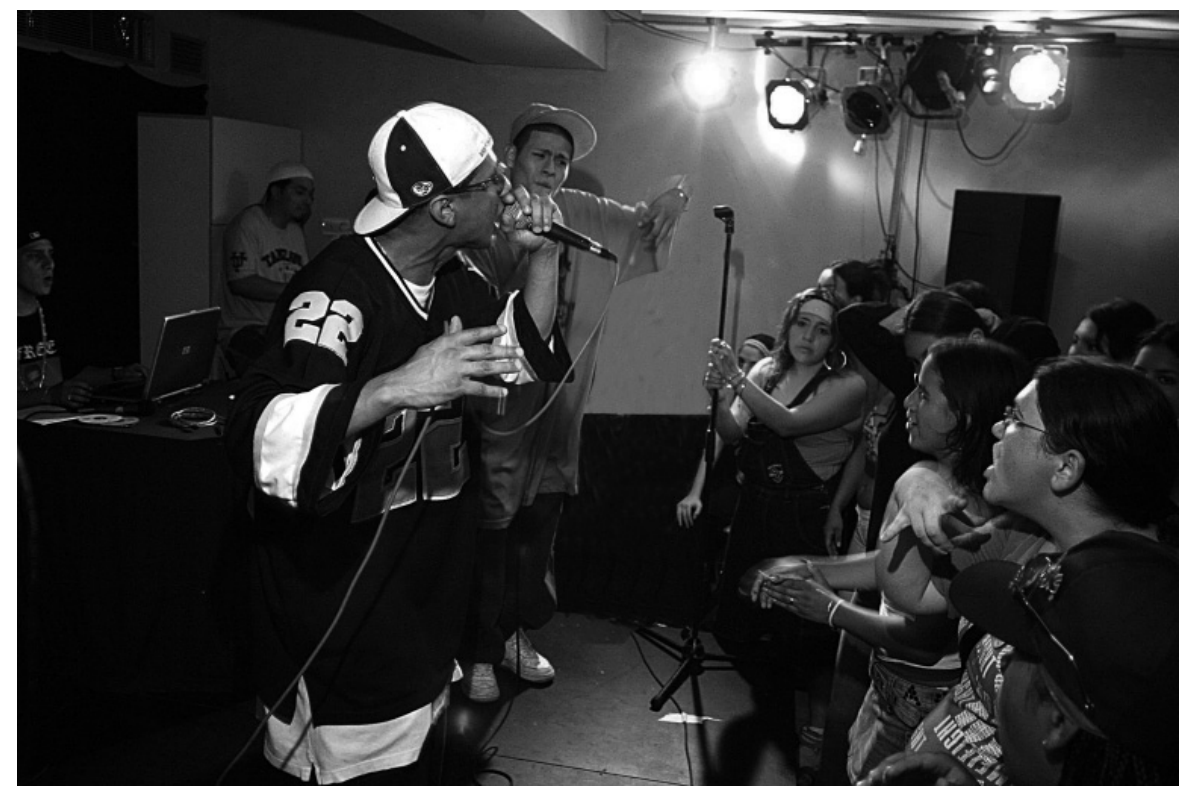

FiguRA 2.-Concierto Uga Records, Organización Cultural de Reyes y Reinas Latinos, Barcelona 2006. Foto de J. C. Martínez.

texto de pobreza y marginación extrema. Descubre y entra en los latin kings durante su adolescencia y, en Ecuador, se implica mucho, hasta el punto de cubrir diferentes roles de responsabilidad y liderazgo intermedio. Empieza una relación con una reina con la cual tiene un hijo y, en el año 2000, deciden emigrar hacia España, dejando a su hijo pequeño bajo el cuidado de la abuela paterna. La migración, por lo tanto, se debe a motivos económicos y de ascensión social personal y familiar, aunque desde un primer momento, la vinculación de César con la Nación se hace evidente. Debido a unos conflictos internos que estaba viviendo la STAE ${ }^{18}$ en España en aquel momento, es elegido $^{19}$ como nuevo líder y seguirá al mando hasta el año 2009.

18 Sagrada Tribu Atahualpa Ecuador, de la que se había fundado un subgrupo en España.

19 El tema de cómo se lleva a cabo la elección del líder es muy interesante ya que según las escrituras sagradas es un cargo electo democráticamente por todas y todos los miembros del grupo. De hecho, presencié el proceso de votación y, finalmente, de reelección de Manaba como líder. Al mismo tiempo, tenemos constancia de que esta práctica muchas veces, y tanto aquí como en Ecuador, fue llevada a cabo de forma arbitraria por un reducido número de reyes. 
King Manaba fue uno de los protagonistas del proceso de transformación de los principios, normas y valores que vivió la organización de los latin kings \& queens en Cataluña, a raíz de la decisión de poner en marcha un proceso de diálogo y de cambio que confluyó en el nacimiento de la Organización Cultural de Reyes y Reinas Latinos en Cataluña ${ }^{20}$. César descubrió la música rap y todos aquellos elementos que se vinculan a este estilo musical cuando era un adolescente. Hasta aquel momento se definía como un rockero y vestía su cuerpo con pantalones estrechos y ropa ajustada casi exclusivamente de color negro. Hacer nuevas amistades significó el descubrimiento de nuevos gustos y nuevas prácticas. La música fue el elemento determinante para acercarse al mundo del rap, primero simplemente como consumidor y luego, al entrar a formar parte de una banda musical, empezó a experimentar una verdadera transformación corporal. Al principio pedía la ropa prestada a sus compañeros y esta práctica, vivida emocionalmente como temporal, le permitía observar su nuevo cuerpo y experimentar sensaciones distintas. Por último, es interesante subrayar cómo estas nuevas experiencias corporales lo alejaron de un imaginario social no particularmente conflictivo, hacia otro profundamente estigmatizado, especialmente en lo referente a las prácticas violentas.

\begin{abstract}
Al principio no me sentía bien, así de la noche a la mañana vestirme así como... yo me sentía como una cosa rara, porque la gente por la calle te queda viendo mal. Me sentía mal, incómodo, como un bicho raro, ¿sabes? Pero ya después empecé a sentir la música, me gustaba la letra de ellos, y que tenían un sentimiento por la ropa, por la forma de vestir, y por la forma de pensar de ellos. Nuestro grupo se llamaba "Los Reyes Caminantes" y cantábamos puro rap, y eso tenía que venir con la ropa, o sea, el estilo de la música que cantábamos tenía que ver con el estilo de tu vestimenta, ¿me entiendes? Me tocaba vestirme así porque ellos me decían: "No vas a ir tú vestido al cuerpo cuando nosotros todos estamos anchos". Entonces me fue gustando poco a poco, ¿no?
\end{abstract}

El aprendizaje musical fue fundamental para pasar de la práctica de "escuchar" la música y ponerse ropa, a "sentir" la música e in-corporar estas nuevas prácticas. Tocar en un grupo de rap y actuar para un público rapero implicaba toda una serie de recursos indispensables para completar la performance. Es decir, las imágenes que emanaban de los cuerpos de cada uno de los miembros del grupo tenían que ser compatibles para fusionarse con

${ }^{20}$ Durante los últimos cinco años se han publicado diferentes trabajos, nacionales e internacionales sobre el proceso de constitución de una asociación juvenil (bautizado por parte de los medios de comunicación como proceso de legalización de las bandas latinas) llevado a cabo por los latin kings \& queens en Cataluña. Entre las muchas publicaciones destacan: Feixa y Canelles (2006) y Romaní, Porzio et al. (2009). 
la imagen global del conjunto. Si Manaba quería actuar con los "Reyes Caminantes" debía respetar unos criterios de homogeneidad entre lo que representaba su cuerpo y el de los otros. Este aprendizaje se fue in-corporando en él hasta que, del gusto por vestirse como un rapero, pasó a sentirse y definirse un rapero. Pero, ¿qué significa y qué implica?

Eh, sinceramente, muchos de nosotros nos consideramos raperos porque nos gusta el hip-hop, el rap. Pero hay mucha gente que ni siquiera sabe la historia del rap, la historia del hip-hop, y se viste ancho, ¿me entiendes? Entonces hay mucha gente que se viste ancho simplemente por llamar la atención, mas no por el sentir de esta forma de vestir, ¿me entiendes? Pero yo... ¿El sentir? La música que viene desde la calle, la música underground, la música que viene de clase muy baja. En sí la ropa ancha viene de la cárcel, ya que les daban la ropa grande, entonces ellos se la ponían y se veía grande, y entonces de ahí salió para la calle...

Existen diferentes maneras de ser rapero, que pueden implicar diferentes prácticas. En el caso de Manaba, el hecho de conocer, escuchar y sentir de forma emotiva el rap son los elementos indispensables para ser rapero y no simplemente aparentarlo. Se hace aquí evidente la relación entre cuerpos representados y cuerpos sentidos ya que ser un rapero auténtico, y no simplemente imitar el modelo, implica adherir a normas corporales y emocionales al mismo tiempo. Hay que saber vestir con gusto, hay que saber escuchar la música pero también hay que vivir todo esto como una emoción fuerte, para obtener autenticidad dentro del grupo. Aunque el relato y los discursos de Manaba buscan constantemente demostrar esta autenticidad, ya veremos más adelante cómo sus prácticas desatienden sus discursos, generando paradojas interesantes entre el rap y los latin kings, entre la ascensión social y la migración, entre cuerpos marcados y cuerpos neutralizados, entre prácticas de resistencia y de asimilación.

\begin{abstract}
Sí, mira, la diferencia que hay es que un rapero, se sabe vestir, sabe combinar la forma de vestirse y sabe lo que es la música, ¿me entiendes? Y sabe escuchar, o sea... Bueno que, la diferencia es que la persona que es rapero tiene que saber combinar la forma de vestir con lo que escucha. Hay mucha gente que no se sabe ni vestir y escuchan rap. Un batracio... un ejemplo es que... que se pongan... que se vistan con ropa ancha y que escuchen David Bisbal. Y más que todo también uno, uno aprende viendo otras personas que han venido de los Estados Unidos: "mira, estas personas se visten así". Yo a un, a un rapero de Guayaquil, que estuvo en Nueva York, él vino para acá, fue a Ecuador, y él se vestía muy bien. Se vestía con botas, con pantalones, entonces yo me comencé a vestir así.
\end{abstract}

Aparentar ser un rapero, es decir, vestir el cuerpo con elementos de indumentaria que representen este estilo, tiene un poder simbólico que 
supera las fronteras de la misma cultura juvenil, ya que crea un imaginario visual y discursivo que vincula estos jóvenes a EE. UU, como la madre patria del rap. Los movimientos y circulación transnacional, entre EE. UU y Latinoamérica, de los elementos corporales y sonoros que definen lo que es y no es rap, crean un circuito de producción y reproducción de imaginarios prácticos y simbólicos que hace que un chico latinoamericano que va de rapero, llegue a sentirse auténtico cuando finalmente logre consumir productos de marcas norteamericanas. Todos estos procesos de significación, individualmente —como jóvenes raperos latinoamericanos- y colectivamente - como miembros de una cultura juvenil- se llevan a cabo desde sus cuerpos representativos y significantes y, al mismo tiempo, emotivos.

No sé, para mí la imagen es lo... para mí la imagen es algo importante, porque no sé, es como que lo que tú sientes por dentro lo demuestras también con la imagen, ¿̇me entiendes? Para mí es un sentir, ¿sabes? Para mí la imagen vale mucho.

Adornar y vestir el cuerpo, por lo tanto, significa manifestar las propias emociones, es decir, representar por fuera lo que se siente y se experimenta por dentro. Su cuerpo individual es el elemento que permite a Manaba situarse en el mapa de los gustos juveniles y le permite expresar y comunicar lo que siente y lo que quiere ser. Podemos hablar de deseos individuales que se entremezclan y se quedan difuminados entre los deseos grupales de otros jóvenes que aparentan ser como él. Estas fuertes emociones pueden perder intensidad y suavizar su representación corporal con el paso del tiempo biográfico, o porque los mismos emblemas del grupo vienen reinterpretados como estigmas (Goffman 1998; Sayad 2002) por el resto de la sociedad.

Yo, por ejemplo hay veces que me entra la locura de vestirme... serio, porque a veces me pongo a pensar el pensamiento de que: "bueno, puede que ya haya pasado mi tiempo de vestirme así, ¿no?”. "Tengo que cambiar algún día.”. No sé, ¿no? Pero igual eso no quiere decir que me deje de gustar el hip-hop o el rap. A veces porque sentía un poco de miedo a llamar la atención, porque tú sabes que esta ropa llama la atención, mucho. Entonces, ¿cómo te va a ver la gente? No te van a ver como una buena persona, te van a ver como lo peor. Por ejemplo, cuando yo vine aquí quería venir así, pero mi mamá me decía: "No, que cómo vas a ir así, no te van a dejar salir, que parece pandillero" y me tocó vestirme con corbata, chaqueta.

En la cita anterior, Manaba explica cómo el deseo constante de representar los propios emblemas se suaviza con el paso del tiempo y puede generar procesos de transformación que inciden en la misma presentación social del cuerpo. Ser adulto y vestir como un "rapero auténtico" pueden ser vividos como elementos contradictorios e impulsar procesos de trans- 
formación que lleven a las y los miembros de cualquier cultura juvenil a identificarse con cánones corporales más hegemónicos y socialmente compartidos. Durante todos estos procesos de identificación, diferenciación y representación, el cuerpo es el elemento que utilizan las y los jóvenes para sentirse y ser reconocidos como miembros de un grupo. Pero, al mismo tiempo, es el elemento que las y los otros jóvenes y la sociedad adulta, utilizan para hacer comprensible y localizable a una persona dentro de un contexto sociocultural específico. Estos juegos de miradas y juicios de valores pueden comportar procesos de estigmatización y exclusión social. Vemos ahora cómo Manaba, en muchas situaciones, se percibió a sí mismo como excluido, tanto en el país de origen como en el país de acogida, a causa de la información que emanaba de su cuerpo.

Desde Ecuador muchas veces me he sentido rechazado por las personas. Sí, un episodio de mi vida fue cuando me llamaron pandillero... que era ladrón. Vecinos míos, que era ladrón, que fumaba drogas, que robaba, solamente por vestirme así. Y aquí, pues aquí en España también me he sentido muchas veces que me han quedado viendo mal, o que a veces yo voy caminando y unas señoras van con la maletita, y me ven y cogen la maleta, la agarran así como que piensen que yo les voy a robar y todo. Porque hay muchas personas que piensan que porque uno va vestido así, uno es el criminal más grande del mundo, pero no hay otra persona que se pone a pensar que el criminal más grande del mundo puede venir de traje y corbata. ¿Me entiendes?

El extracto de entrevista anterior es muy interesante para reflexionar sobre la relación entre el cuerpo de las y los jóvenes, y las diferentes implicaciones que generan los contextos en que se encuentra arraigado. La estética rapera en Ecuador crea y produce un imaginario social que la vincula a la violencia y criminalidad (Cerbino y Rodriguez 2008). En España, como ya se ha señalado anteriormente, existe un discurso mediático que afecta el imaginario social, que relaciona la estética rapera con ser un chico de "bandas", y por lo tanto, un violento, no adaptado y no integrado. Manaba, en cambio, explica que la vestimenta rapera no forma parte de la cosmovisión latin kings.

Las escrituras sagradas del grupo hacen referencia a toda una serie de normas corporales que afectan la presentación social del cuerpo de las y los reyes en determinadas situaciones, por ejemplo, marcando el color de la ropa durante las reuniones, pero nunca su estilo. Sin embargo, la influencia de la industria cultural popular norteamericana, que difunde mundialmente los estereotipos de la vida de gangster mediante la música, los videoclips y una extensa producción cinematográfica, es muy determinante entre la juventud en Latinoamérica, especialmente en las clases trabajadoras y en los grupos sociales más desfavorecidos. Esto hace que la gran mayoría de re- 
yes $^{21}$ vistan su cuerpos según el estilo rapero, no porque esto sea un símbolo de los latin kings, sino más bien para expresar los gustos musicales y corporales de la gran mayoría de chicos de sus países de origen y de su medio social. El reggaeton también forma para del gusto musical mayoritario entre las reinas y los reyes, que lo prefieren en situaciones de ocio y de baile. En el relato de Manaba, pero también en otras entrevistas, las chicas y los chicos remarcaban una diferencia importante entre el rap como un estilo de música para expresar ideas, sentimientos, identidad, etc. y el reggaeton como una música para bailar y divertirse.

Mira, yo te puedo explicar que muchas veces hay personas que no son reyes y se visten rapero. Pero... yo mismo cuando veo un rapero por la calle, pienso: "AAlgo será! O será Rey o será Ñeta”22. Pero más que todo, los reyes se identifican porque ya esta cultura ya la conocieron y les gustó, ¿me entiendes? Y se comenzaron a vestir así desde Nueva York, ¿me entiendes?

Para acabar, uno de los elementos interesantes que emerge de la cita anterior, es cómo el proceso de construcción del imaginario que vincula el rap a los latin kings acaba influyendo a las mismas y los mismos jóvenes que lo viven en cuanto lo reproducen y refuerzan con sus discursos y prácticas.

Todas estas prácticas corporales significantes descritas hasta ahora tienen, o pueden tener, un carácter temporal, puesto que se puede modificar la forma de vestir y elegir otras expresiones y otros significados. Pero, ¿qué pasa cuando los cuerpos se marcan irreversiblemente con un tatuaje?

\section{CUERPOS TATUADOS, CUERPOS SIGNIFICANTES. VISTO Y NO VISTO, ENTRE EL DESEO Y EL RECHAZO}

Mi primer tatuaje lo hice hace... hace aproximadamente unos 7,8 años y fue el que tengo aquí en el pecho. Pues mira, este fue muy doloroso porque fue con una máquina de esas... caseras que hacían antes los hermanitos allá en Ecuador con un boli de marca Bic... Le ponen una máquina de cochecito de control remoto... Y las agujas eran agujas normales, ¿me entiendes?

${ }^{21}$ Las reinas, en cambio, visten imitando el modelo de chicas sexi y provocativas inspirado en artistas como Beyonce y Jennifer Lopez.

${ }^{22}$ Asociación Ñeta, Asociación Pro-derecho de las/los Confinados. Organización juvenil de calle que nace en las cárceles de EE. UU y luego, como los latin kings, llega a Latinoamérica y, por las migraciones transnacionales, a Europa. En Cataluña, también constituyeron una asociación cultural con estatuto legal. Para entrar en materia, existen diferentes publicaciones nacionales e internacionales como las ya citadas de Brotherton y Barrios (2004) y Feixa, Porzio y Recio (2006). 
King Manaba se tatúa por primera vez para representar su organización: los reyes latinos. El tatuaje fue realizado por un hermanito ${ }^{23}$ con técnica y herramientas improvisadas. Este hecho dota de un sentido ritual importante a la misma práctica, puesto que el protagonista de esta historia decide marcarse sin dar importancia a la dimensión estética del dibujo y, por lo tanto, la manera en que su cuerpo quedaría adornado.

Como tú podrás ver, tenemos la bandera de Cuba en honor a nuestro hermanito King Blood que fue el fundador de la tribu de los Leones allá en Nueva York. Y la bandera de Ecuador... por los hermanitos que se encuentran en el Ecuador. Tengo la Corona, que es el emblema que nos representa a nosotros como reyes y reinas, tenemos nuestro collar en dorado y negro. Eh, las cartas, las barajas... La $\mathrm{K}$ de rey de corazones y la $\mathrm{Q}$ de reina corazones, porque... realmente pues... la carta significa que nosotros debemos llevar el rey dentro de nuestro corazón, y la reina dentro de nuestros corazones. Debajo de las cartas pues tenemos el león y la leona... pues como sabes son los... el rey de la selva, entonces nosotros lo hemos tomado como, como el rey de los latin kings también. Y tenemos los cinco diamantes que es vista, oído, gusto, tacto y olfato, ¿me entiendes? La rosa negra que es nuestro código de silencio, ¿me entiendes?

La Todopoderosa Nación de Reyes y Reinas Latinos se presenta con un icono en su pecho donde se reproducen todos los símbolos del grupo: la bandera, la corona, las cartas, etc. Resulta particularmente interesante la metáfora corporal de los cinco sentidos representados mediante cinco diamantes que adornan las cinco puntas de la corona: la vista que es para ver y reconocer los propios hermanitos/hermanitas; la escucha que es para escucharlos/las si se encuentran en dificultades; el tacto hace alusión a la necesidad de transmitir amor entre ellos y su grupo, la Nación; el olfato sirve para percibir los peligros y las amenazas que, si son superadas, se aprecia en honor a la magnitud de la Nación. Ser un rey latino, para King Manaba, es un orgullo y quiere representarlo mediante un tatuaje. Un tatuaje situado cerca del corazón, con todos los símbolos de la Nación dibujados y grabados. Un dibujo impreso en la piel como síntesis de su pertenencia y vinculo al grupo.

Bueno, el día que me lo hice... era mi primer tatuaje joder, y yo digo bueno... Me hice un tatuaje porque... quería ya sentirme marcado, ¿me entiendes? Quería ya sentirme identificado. Porque... quería mucho a la Nación, la respetaba, entonces yo quería llevar algo en el cuerpo, que me represente, y a los demás también. Pero fue algo... fue una experiencia muy bonita para mí, inolvidable..., y salía bastante sangre, ¿sabes? Entonces dolía mucho, me dolía bastantísimo. Y... me decía el hermanito: "Es para que nunca te olvides de mî" [Risas].

${ }^{23}$ Hermanito/Hermanita es un apelativo coloquial y amistoso que utilizan entre ellos, en las organizaciones juveniles de calle. 


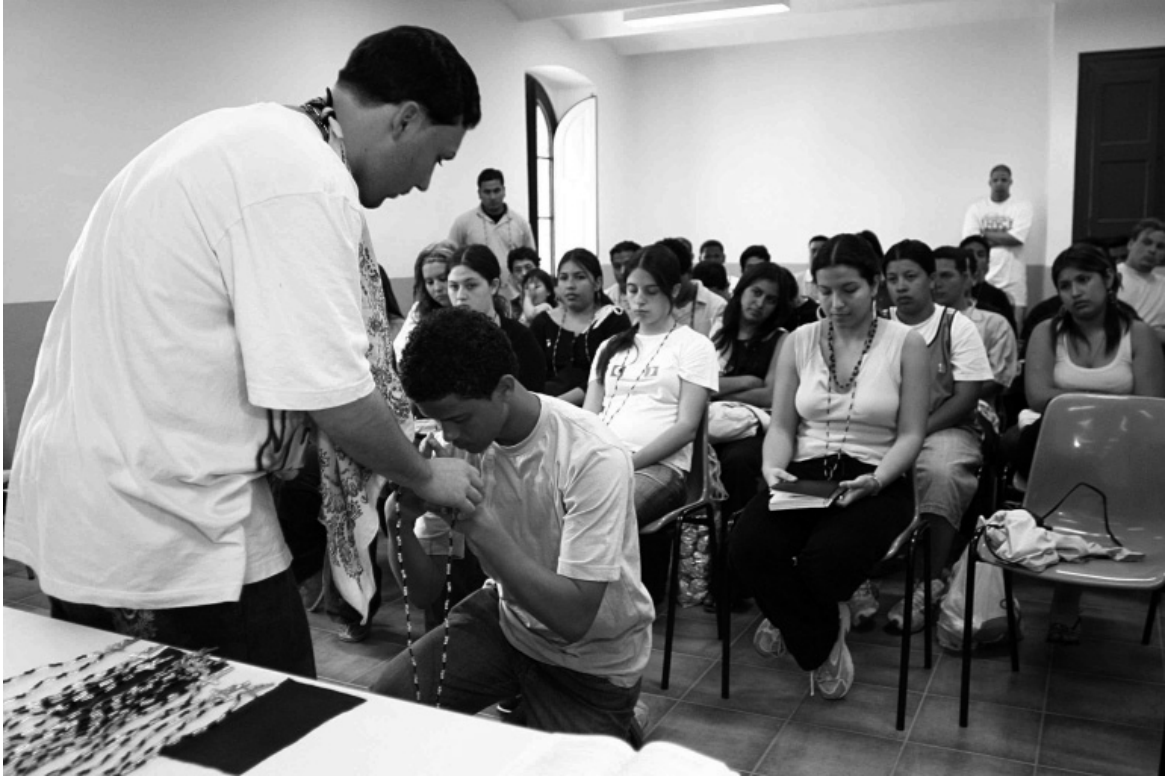

FIguRA 3.-Coronación. Reunión Sagrada del Sol. Todopoderosa Nación de los Latin Kings \& Queens, Barcelona, 2006. Foto de J. C. Martínez.

Durante el proceso de aprendizaje que vive cualquier hermanita y hermanito antes de ser coronado, y por lo tanto renacer como miembro efectivo del grupo, se aprenden las normas y las prohibiciones que afectan a la presentación social del cuerpo. Representar la Nación implica llevar vestimentas que combinen los colores amarillo y negro, saber saludar haciendo el símbolo de su corona con las manos y aprender cuándo se debe y cuándo se puede ${ }^{24}$; llevar el collar que le dieron durante la ceremonia de coronación ${ }^{25}$ y que representa, de hecho, la corona de los reyes latinos ( $\mathrm{Fi}$ gura 3).

Manaba explica que después de haber in-corporado y transformado en

${ }^{24}$ Los collares se deben llevar en las reuniones y actos rituales, no se aconseja llevarlos en situaciones de actividades lúdicas o de socialización cotidiana y no se pueden llevar si se consume alcohol.

${ }^{25}$ La ceremonia de coronación es el momento ritual donde culmina el proceso de aprendizaje y, parecido al bautismo católico o a un rito pentecostal, simboliza el renacimiento de las chicas y de los chicos. La ceremonia la conduce el Inca y consiste en sumergir los collares en agua previamente consagrada para después pasarlos por la cabeza del nuevo miembro pronunciando su nuevo nombre (AKA) como rey. Por ejemplo de César a King Manaba. 
experiencia todas estas prácticas, llegó el momento en que decidió verse marcado de una forma más profunda e indeleble:

Cuando acabó, yo estaba impresionado, yo estaba muy contento y yo andaba sin camiseta por ahí por la calle, así con la gente que pasaba. Los hermanitos me decían: "Amor de Rey hermano, está, está lindo tu tatuaje, está representativo", y yo me sentía orgulloso de lo que yo cargaba aquí en mi pecho, ¿me entiendes? En ese tiempo yo tenía casi unos 3 años o 4 años de ser rey. Y tenía... pues hablamos de unos 18 más o menos. Y estaba en una edad que quería presumir de muy malo, de que llevo tatuajes y todo eso.

En esta parte del itinerario, Manaba describe y reflexiona sobre dos temas muy interesantes: la relación entre edad y deseo de representación y la idea de cuerpo estigmatizado. Cuando era más joven necesitaba expresar ser un rey latino en cualquier momento y contexto, pero conforme al paso del tiempo, su relación con la práctica del tatuaje ha ido cambiando. Durante su adolescencia y primera juventud en el Ecuador, su cuerpo marcado era un canal para expresar su identidad corporal y su actitud rebelde con respecto a la sociedad de la cual se sentía marginado. Aparentar ser malo, haciendo su cuerpo fuertemente visual, significativo y reconocible, representaba una práctica de resistencia simbólica (Hall 1975) que se incorporaba y determinaba cotidianamente su itinerario biográfico. Podemos decir que la relación con su cuerpo tatuado recorría un camino desde el corazón y sus emociones, hasta la superficie del cuerpo: su piel. Con el paso del tiempo este sentimiento fue cambiando y la marca permanente recorrió el camino invertido. Durante la entrevista, me dijo que se estaba planteando modificar sus tatuajes que lo identificaban como latin king, ya que podían llegar a ser un obstáculo para algunos de los objetivos de su proceso migratorio: la inclusión y aceptación social. El proceso migratorio en un nuevo contexto en donde los latin kings son una organización mediática y estigmatizada, induce un cambio importante en sus prácticas: mientras que durante su adolescencia en el Ecuador, con tal de enseñar sus tatuajes, iba por la calle sin camiseta, en la actualidad prefiere tapar estos mismos símbolos y, aquí y ahora, no se quita la camiseta ni cuando está en la playa.

Pero mira que ahora ya... casi no... me molan los tatuajes pero para uso personal, ¿me entiendes? Ahora cuando voy a la playa me baño con camiseta... Porque no quiero enseñarlo. Ese tatuaje sale en las noticias, sale en todos lados. No me molesta que piensen que soy latin king, me molesta que malinterpreten las cosas, ¿me entiendes? porque... si me ven como un latin king me voy a sentir orgulloso siempre, pero me molesta que cojan los bolsos porque piensen que les voy a robar, o que si yo estoy de un lado en la playa, en la arena, no me puedo acostar ahí, porque si me acuesto ahí, toda la gente de alrededor se va a otro lado. Eso me ha pasado. 
Los tatuajes de Manaba representan el orgullo de pertenecer a la Nación de manera fuerte y claramente significativa. Actualmente en Occidente, un cuerpo tatuado llama la atención si el dibujo es grande y visible, y/ o tiene una carga simbólica importante, como por ejemplo llevar una corona con un pergamino que dice latin king. Situar a una persona en un contexto sociocultural específico mediante lo que emana de su cuerpo es una práctica común en las interacciones cotidianas entre individuos, que no sólo se genera cuando los cuerpos están marcados permanentemente, sino más bien cuando manifiestan una corporalidad u otra (Goffman 1998).

Las reflexiones de César sobre sus prácticas corporales y los procesos de estigmatización que padece a causa de su extrema visibilidad parecen reivindicar el deseo de reapropiarse de su cuerpo. Un cuerpo libre de hacer, expresar y representar emblemas sin modificarlos, suavizarlos o volverlos invisibles para adaptarse a los criterios sociales y hegemónicos impuestos. Ahora bien, si nos centramos en sus experiencias y vivencias como King Manaba, líder de la Todopoderosa Nación, vemos que su discurso y las prácticas vinculadas vuelven a priorizar la centralidad del cuerpo pero esta vez como herramienta de control y de normativización dentro del grupo.

Bueno, es que sinceramente por ejemplo nosotros aquí en la Nación nosotros tenemos una regla de que los reyes que tengan menos de dos años no pueden tatuarse nada que tenga que ver con la Nación ime entiendes? Pero... igual, el tatuaje que te quieres hacer tiene que ser supervisado y tienen que darle el significado, eh, a los hermanitos que están de encargados, de oficiales, para saber qué tú llevas de tatuaje.

En esta parte del itinerario, Manaba nos presenta una paradoja interesante que nos permite reflexionar sobre la relación entre el cuerpo individual y subjetivo de las reinas y reyes como jóvenes, y su representación colectiva en el seno de prácticas expresivas, pero también normativas y estructurales, que marcan el funcionamiento y los significados del mismo grupo. La espontaneidad y libertad corporal que reclama César en otras partes de su biografía, como por ejemplo cuando denuncia el proceso de estigmatización del rap y los raperos, o la vinculación de los latin kings con prácticas violentas y delictivas, cambia de orientación cuando se refiere a su rol y a sus acciones como líder de la Nación. Los cuerpos vestidos y tatuados de las reinas y de los reyes siguen una rígida normativización, ya que tienen que respetar las leyes que los atañen y, por lo tanto, enmarcar sus cuerpos individuales dentro de las normas colectivas relativas a la simbología de los latin Kings:

Vi a uno con un collar amarillo con negro. Y... No, no sabía lo que era, yo le digo: “¿Dónde compraste ese collar, que está muy bonito?”, y me dice: "En Gua- 
yaquil me lo dieron", y: "Cómprame uno", le digo así, me dice: "No, es que tú tienes que ganártelo", me dice. "Sí, tienes que pasar por pruebas y...", entonces ahí me conversó, "Tú tienes que hacerte esto, y esto, y esto, tienes que pasar etapas". Entonces lo hice, en 3 meses fui rey [risas]. 3 meses, jsi es fácil ser rey!

En muchas de las entrevistas realizadas se repite la idea de que son las imágenes corporales y los mensajes visuales los que captan la atención de las personas que aún no conforman el grupo. Algunas se centran en los colores amarillo y negro de la ropa y adornos, y Manaba se refiere a los collares que, como ya se ha explicado a lo largo del texto, representan metafóricamente su corona, símbolo de la realeza de la Nación. La ritualidad y las creencias de los latin kings se pueden definir como sincréticas, ya que toman, seleccionan y mezclan objetos y prácticas de la doctrina católica con otras religiones como la santería. Cada símbolo y cada elemento visual tienen un significado y una razón de ser, es decir, no están elegidos al azar, sino más bien in-corporados en la cosmovisión global. Llevar el collar de pepitas negras y doradas (Black \& Gold) significa ser un rey latino y representar con orgullo la propia Nación.

Cuando lo llevo, lo llevo porque tengo que ir a rendirle homenaje, tengo que irle a rezar, ¿me entiendes? Porque yo sé que cada mes tengo que rendirle homenaje a mi collar, a mi corona ${ }^{26}$. Pero de ahí a todos los otros días creo que yo me siento un rey igual, y llevo los colores igual, pero creo que es un objeto no más. Antes yo lo llevaba siempre, me bañaba con el collar.

Bueno, yo esto... tenía unos 6 años de ser rey, que hasta ahí que había la enfermedad del collar. Yo por eso me doy cuenta que cuando uno recién es rey, tiene ese entusiasmo, esas ganas de querer usar tu corona, porque te sientes orgulloso de habértela ganado, de haberla obtenido, te sientes orgulloso de lo que representa.

Los significados y usos rituales de los collares, como ya se ha explicado, son normativos, es decir hay leyes que regulan cuándo se tienen que llevar y cuándo está prohibido. Durante las actividades rutinarias de la vida cotidiana se deja la elección a las y los hermanitos. También en el caso de los collares, al igual que los tatuajes, la relación entre deseo de representación y sentimientos más íntimos es proporcional al momento biográfico que se está experimentado. En otras palabras, cuando se entra en el grupo, el deseo de ser reconocido es muy fuerte y las y los chicos llevan sus símbo-

${ }^{26}$ Cada mes se realiza la reunión Sagrada del Sol, donde participan las y los miembros de toda la tribu (España) y en la que se realizan actividades rituales, lúdicas, iniciativas que refuerzan la hermandad entre hermanitas y hermanitos, etc. En esta parte de la entrevista César subraya la obligación de llevar el collar en esta reunión. 
los siempre y en todo lugar. Con el paso del tiempo este deseo se atenúa y se hace menos visible:

Quieres decir "amor de rey" ${ }^{27}$ a cada momento [risas]. Porque... eh, es la emoción, de algo que decir: "Por fin he logrado algo con mi esfuerzo", ¿̇me entiendes? Como por ejemplo cuando tú tienes una obsesión de conseguir algo, por ejemplo mi obsesión es tener mi estudio de grabación. Y yo apuesto que tengo mi estudio de grabación, y dormiría ahí, no me iría de ahí, no iría a casa, sino estar ahí. Hasta que ya poco a poco vas asimilando de que... iya esto va a estar ahí! O sea, de que tienes que ver otras cosas, pero el estudio siempre va a estar ahí, el collar siempre va a estar ahí [risas]. Tú siempre vas a ser un rey, hay que hacer otras cosas, ¿me entiendes?

Amor de Rey/Reina es la evocación ritual que los hermanitos y las hermanitas intercambian cuando se encuentran para saludarse. Esta salutación verbal se acompaña de una gestualidad corporal que recrea la forma de una corona mediante un típico cruce de manos que parten del corazón y llegan al cielo. Las reinas y los reyes que acaban de ser coronados buscan situaciones para poder expresarse verbalmente y chillar con emoción un Amor de Rey. Como explica Manaba, los hay que llegan al punto que "si te vas al baño, cuando regresas te saludan de nuevo porque es algo, como que te digo, emocionante." Estas fases que describe Manaba aparecen descritas textualmente dentro de la cosmovisión latin kings como las Tres Etapas:

Hay tres etapas, la etapa del estado primitivo que es una etapa cuando uno lo coronan... uno quiere ser el más malo que todos, uno quiere utilizar todo lo que haya, uno quiere saludar a todo el mundo. Eh, si me quedan mirando en la esquina yo cojo y le entro a puñete, eh... el estado primitivo. El estado conservativo, es cuando ya te pones dudas, el estado conservativo es la etapa momia, estás... "peleo, pero a la vez ya como que no me interesa mucho, ando por ahí, quiero hacer mi vida...", ¿me entiendes? La etapa del nuevo rey es la etapa... que el rey cuando ya decide tener su hogar, con su mujer. Ya los dejas a un lado, lo tienes guardadito. Él sabe que es un rey, pero ya no es lo mismo como en el estado primitivo que pelea por su collar, muere por su collar, y todo eso, sí. La etapa del nuevo rey es cuando ya el rey decide, quiere seguir siendo un rey, pero quiere dedicarse más a su familia, a su mujer, a su pareja, a sus hijos si los tiene... Ya no anda por las calles peleando, ya no está en las esquinas parando, ya se dedica a otras cosas más productivas, a lo que tenga que beneficie a la Nación, y lo beneficie a él también. A trabajar, a hacer algo productivo por la Nación y por él, claro.

La etapa denominada primitiva es la de la representación extrema de los símbolos y donde las actitudes son más intensas. Después de un tiem-

${ }^{27}$ Exclamación que utilizan al saludarse. 
po, ya no hace falta expresar con tanta virulencia que se pertenece al grupo, ya que sus símbolos están in-corporados y no se siente la necesidad de demostrar ni manifestar lo que uno es o siente que es. Durante la etapa conservativa aparece el deseo de estar de forma diferente dentro de la Nación, dejando ya la idea de que se debe pelear para defender el nombre del grupo. Esta etapa que Manaba denomina momia es la que prepara el último estadio que es el nuevo rey, que trabaja para el grupo, pero que empieza a tener en cuenta sus propias necesidades y que defiende una forma únicamente ritual de ser un rey, y ya no se busca la idea de "que ser latin king es ser malo, ser aquí en plan de respeto".

Cuando ya no seré el Inca... me gustaría llegar a ser un consejero, un consejero para los nuevos hermanitos que vengan. El consejero aconseja a los hermanitos, a los nuevos líderes, pero nunca quisiera desvincularme de la Nación. Y si me desaparezco, pues me desapareceré. Tomarme mis vacaciones, ¿no? Porque son ya casi 12 años sin poder descansar. Sí, son 12 años de estar en la Nación, y quiero... a ver, también quiero poner mis ideas en hacer otras cosas, por ejemplo, traer a mi hijo... Pero también en 12 años no hubiera sido un rey, y no hubiera conseguido lo que se ha conseguido ahora. Eh... porque yo antes de entrar en la Nación, yo era futbolista, yo jugaba en un equipo profesional en Santo Domingo $^{28}$, y a lo mejor, ¿qué hubiera pasado de mi vida? Tampoco me arrepiento de haber estado aquí, eh, lo que yo sí te digo es que tomarme un tiempo sí quiero. Pero... no para alejarme, no para dejar de seguir siendo un latin king.

En esta última parte de la entrevista, aparecen de forma clara y sistemática las tensiones constantes entre lo individual y lo social que han ido apareciendo durante todo el relato. La tensión hacía lo colectivo, y por lo tanto hacia su grupo de referencia, que parecía tener más peso, se ha ido atenuando con los años y el ingreso a la vida adulta. El deseo de tomarse unas vacaciones resitúa esta tensión hacia la reapropiación de las propias necesidades como individuo y no tanto como rey. Este cambio de orientación se ve reflejado en el cuerpo, donde las marcas permanentes y significativas se están suavizando o, incluso borrando.

\section{REFLEXIONES FINALES}

En este texto se ha analizado cómo la presentación social del cuerpo constituye un eje fundamental para construir y representar identidades, tanto en los procesos biográficos individuales, como en lo referente a las culturas y/o organizaciones juveniles y cómo —al mismo tiempo- influye en los

\footnotetext{
${ }^{28}$ Ciudad natal del César situada en el interior ecuatoriano, entre la costa y la sierra.
} 
procesos de cambio social. En otras palabras, mediante el estudio de caso de los procesos de transformación que Manaba vivió como joven, como rapero y finalmente como rey latino, se han introducido elementos que tienen un alcance más amplio y llegan a explicar qué significa ser un rapero en Ecuador y en España. Vemos también cómo visten sus cuerpos los raperos y lo que pretenden representar con estas mismas prácticas corporales. También se ha podido entrar en aspectos concretos de la cosmovisión latin king, cómo sus rituales y sus normas corporales que forman parte del aprendizaje de cualquier chica y chico que quiera pertenecer a la organización.

Una de las conclusiones que quiero subrayar es que el cuerpo es un elemento central a la hora de representar emblemas identitarios como la vestimenta rapera que vincula la persona a un gusto musical y a un cierto discurso reivindicativo. Sin embargo, este mismo cuerpo puede representar un estigma, ya que se vincula a prácticas delictivas, violentas y desviadas, por parte de los discursos hegemónicos y los imaginarios sociales que desprenden de ellos. La construcción social (Berger y Luckman 2005) de las y los latin kings, y por lo tanto la idea general que la sociedad de acogida tiene sobre este grupo, es que los chicos que visten como raperos son, sin ninguna duda, miembros de una "banda latina". La representación del cuerpo influye directamente en la presentación social de las organizaciones juveniles de calle, ya que tiene un impacto visual directo y fácil de in-corporar por el conjunto de la sociedad que, de este modo, puede clasificar y ordenar, según los criterios hegemónicos, los nuevos fenómenos sociales que van apareciendo (Canelles 2008). La música rap y la vestimenta rapera no pertenecen directamente a la cosmovisión latin kings, sino que representan el gusto mayoritario de sus miembros, tal y como le pasa a la juventud de clase trabajadora de sus países de origen. Vestir rapero no significa ser un latin king y no forma parte de las rígidas normas corporales que regulan la pertenencia al grupo, como llevar ropa de color amarillo y negro en las reuniones, la prohibición sobre el uso de los collares, los tabúes que afectan a los tatuajes, etc.

La comprensión de un fenómeno de tal magnitud que se refiere a temáticas amplias y heterogéneas como los procesos migratorios, los cambios estructurales en los grupos de edad, procesos de intervención relativos a temas de convivencia o espacio público, etc., no tiene que focalizarse en esta suerte de descripciones que vinculan imágenes a prácticas delictivas y desviantes, produciendo así modelos de análisis empobrecidos. El uso y la presentación del cuerpo en las y los latin king es un tema interesante que puede generar modelos de comprensión más amplios que se refieren, tanto a los significados y a los porqués del mismo grupo, como a cosmovisiones de otras culturas juveniles u otro tipo de asociaciones. Por citar algún ejem- 
plo, el relato de Manaba sobre cómo va cambiando con el tiempo la intensidad emocional y práctica de querer ser reconocido como un rey latino se centra directamente en las transformaciones que sufre y experimenta su cuerpo. Durante la adolescencia y sus primeros años como rey su deseo de ser visto se expresa mediante un cuerpo marcado de colores, collares y de tatuajes que representan sin ninguna duda a los reyes latinos. Con el paso del tiempo y la llegada de la madurez entra en una etapa más reflexiva que busca formas más íntimas de relacionarse con su realidad, hasta el punto de querer cubrir o modificar aquellos tatuajes que antes se enseñaban con orgullo. También quiero remarcar cómo estos cambios, que se relatan a nivel individual pero que explican prácticas colectivas de los grupos en contextos estructurales definidos, como por ejemplo Ecuador y España, vuelven a introducir en el análisis las tensiones entre emblemas y estigmas sociales y procesos de resistencia y/o asimilación.

Este artículo ha explorado diferentes usos y representaciones corporales que nos sirven para pensar en los procesos de resistencia como un conjunto complejo de ideas y comportamientos que se construye mediante la interacción y las percepciones entre las personas que intentan resistirse a los modelos, normes y valores hegemónicos, las personas y/o el medio social a los que se oponen, es decir la clase dominante y las personas que valoran estas acciones como resistentes (Hollander y Einwohner 2004: 549). Todos estos discursos son muy interesantes para pensar que los procesos de resistencia - hacia las desigualdades sociales, hacia patrones culturales, hacia procesos de estigmatización, etc.- que desde las ciencias sociales podemos analizar no son nunca homogéneos y siempre se generan sobre la base de una tensión constante entre resistencia y asimilación. Las experiencias corporales de Manaba manifiestan estas mismas tensiones ya que, en el relato, aparecen prácticas de resistencia abiertas y declaradas, como el deseo de vestir al estilo rapero o de tatuarse símbolos latin king, para expresar su rechazo hacia una sociedad que no ofrece posibilidad de ascensión social a los pobres y desfavorecidos. Pero al mismo tiempo encontramos un cuerpo que, en el nuevo contexto migratorio, decide adaptarse a los mecanismos sociales dominantes y empieza a borrar sus emblemas — cubrir los tatuajes que lo vinculan a la Nación, no vestir rapero, no llevar símbolos de su grupo, etc.para pasar desapercibido y así obtener la plena aceptación social. En este caso, hablaríamos de un tipo de resistencia que Hollander y Einwohner (2004) llaman encubierta y que generalmente caracteriza las acciones de los grupos sociales más pobres y sin agencia adjudicada. Brotherton (2010), al que ya me he referido en diferentes ocasiones a lo largo de este artículo, subraya la necesidad de recuperar la perspectiva de la resistencia en el análisis de las organizaciones juveniles de calle. En lo que se refiere al estudio de caso de 
la Nación de Nueva York, explica la perspectiva de la resistencia mediante la adhesión del grupo a acciones políticas de protesta, para cerrar las bases militares estadounidenses extranjeras, liberar a los presos o denunciar la represión y brutalidad policial (Brotherton 2010: 41).

En referencia a nuestro contexto de investigación, como ya hicimos en otras publicaciones, resulta difícil incorporar este modelo de análisis a los grupos locales. Por un lado, por la falta de un discurso y de una práctica explícitamente política y, por el otro, porque muchos de los valores sobre los que se apoya el grupo responden a un ideario conservador y tradicional (Romaní, Porzio et al. 2009). Pero, lo que me parece más interesante de todo este discurso alrededor de la resistencia es centrar la mirada en aquellas prácticas cotidianas que, sin ser abiertamente resistentes, producen unos cambios en las vidas de las y los chicos y, a largo plazo, pueden llegar a producir un cambio social. La Nación de los latin kings y de las latin queens en un contexto migratorio europeo puede ser interpretada como una respuesta transnacional a la marginación (Brotherton 2010: 40). La Nación de los latin kings y de las latin queens puede llegar a constituir una nueva familia que sirve para luchar contra procesos de inferioridad/vulnerabilidad que produce la condición de migrantes (Canneralla y Queirolo 2007). La Nación de los latin kings y de las latin queens potencia los valores de solidaridad y ayuda mutua mediante una estructura organizativa y afectiva que ofrece una nueva identidad y un nuevo estatus a las reinas y a los reyes latinos. Para acabar, en el caso de los latin kings $\varepsilon$ queens nos encontramos con una organización juvenil de calle que vive, en su propio cuerpo, todas estas tensiones proponiendo y realizando prácticas corporales simbólicas que se resisten y al mismo tiempo se asimilan. Todo para luchar de una forma u otra contra procesos de exclusión como jóvenes, migrantes y pobres.

\section{BIBLIOGRAFÍA CITADA}

Barrios, L. 2008. "Los hijos e hijas de Mamá Tingó: Culturas juveniles y violencia en un proyecto llamado Palenque", en M. Cerbino y L. Barrios (eds.), Otras naciones. Jóvenes, transnacionalismo y exclusión: 165-198. Quito: FLACSO.

Berger, P. y T. Luckmann. 2005. La construcción social de la realidad. Buenos Aires: Amorrurtu.

Blackman, L. 2008. The Body: the Key Concepts. Oxford: Berg.

Bourdieu, P. 1977. Outline of a Theory of Practice. Cambridge: Cambridge University Press. Bourdieu, P. 1983. La distinzione. Critica sociale del gusto. Bolonia: Il Mulino.

Brotherton, D. 2010. "Oltre la riproduzione sociale. Reintrodurre la resistenza nella teoria sulle bande”, en L. Queirolo Palmas (ed.), Atlantico Latino: gang giovanili e culture transnazionali: 29-45. Roma: Carocci Editore. 
Brotherton, D. y L. Barrios. 2004. The Almighty Latin King and Queen Nation. Street Politics and the Transformation of a New York City Gang. Nueva York: Columbia University Press.

Canelles, N. 2008. "Jóvenes latinos en Barcelona: la construcción social de las bandas", en M. Cerbino y L. Barrios (eds.), Otras naciones. Jóvenes, transnacionalismo y exclusión: 95-111. Quito: FLACSO.

Canneralla, M.; F. Lagomarsino y L. Queirolo Palmas. 2007. Hermanitos. Vita e politica della Strada tra $i$ giovani latinos in Italia. Verona: Ombre Corte.

Cerbino, M. y L. Barrios. 2008. Otras naciones. Jóvenes, transnacionalismo y exclusión. Quito: FLACSO.

Cerbino, M. y A. Rodríguez. 2008. "La Nación imaginada de los Latin Kings, mimetismo, colonialidad y transnacionalismo", en M. Cerbino, M. y L. Barrios (eds.), Otras naciones. Jóvenes, transnacionalismo y exclusión: 41-74. Quito: FLACSO.

Choen, S. 1972. Folk Devils and Moral Panics: The Creation of the Mods and Rockers. Londres: McGibbon and Kee.

Comelles, J. M. 1998. "Sociedad, salud y enfermedad: los procesos asistenciales". Trabajo social y salud 29: 151-162.

Csordas, T. 1990. "Embodiment as a paradigm for the antropology". Ethos 18 (1): 5-47.

Csordas, T. 2005 [1994]. Embodiment and experience. The existential ground of culture and self. Cambridge: Cambridge University Press.

Douglas, M. 1998 [1970]. Simbolos naturales. Madrid: Alianza

Entwistile, J. 2002. El cuerpo y la moda. Una visión sociológica. Barcelona: Paidós.

Esteban, M. L. 2004 Antropología del cuerpo. Género, itinerarios corporales, identidad y cambio. Barcelona: Ediciones Bellaterra.

Esteban, M. L. 2008. "Etnografía, itinerarios corporales y cambio social. Apuntes teóricos y metodológicos", en E. Imaz (ed.), La materialidad de la identidad: 135-158. Donostia: Editorial Hariadna.

Featherstone, M. 2007 [1991]. Consumer Culture and Postmodernism. Londres: Sage.

Feixa, C. 1998. De jóvenes, bandas y tribus. Barcelona: Ariel.

Feixa, C. y N. Canelles. 2006. "De bandas latinas a organizaciones juveniles. La experiencia de Barcelona”. Jóvenes. Revista de estudios sobre juventud 10-24: 40-56.

Feixa, C.; L. Porzio y C. Recio. 2006. Jóvenes 'latinos' en Barcelona. Espacio público y cultura urbana. Barcelona: Anthropos.

Feixa, C.; L. Giliberti. et al. 2008. A Case Study on Transnacional Migrant Routh: The Cultural Organization of Latin kings \& Queens in Catalonia. Tresegy, VIth

Framework Program, Universitat de Lleida, Informe inédito.

Ferrándiz, F. 1995. "Itinerarios de un médium: espiritismo y vida cotidiana en la Venezuela contemporánea". Antropología, 10: 133-166.

Ferrarotti, F. 1997 [1981]. Storia e Storie di vita. Roma-Bari: Laterza.

Foot Whyte, W. 1972 [1943]. La sociedad de las esquinas. México: Diáfora.

Foucault, M. 1998 [1975]. Vigilar y Castigar. Madrid: Siglo XXI.

Fraser, M. y M. Greco (eds.). 2005. The Body. A Reader. Nueva York-Oxford: Routledge.

Gatens, M. 1996. Imaginary Bodies: Ethics, Power and Corporeality. Londres y Nueva York: Routledge.

Gramsci, A. 1975 [1929-1933]. Quaderni dal carcere. Roma: Editori Riuniti.

Gofmann, I. 1998 [1963]. Estigma. La identidad deteriorada. Buenos Aires: Amorrortu.

Grosz, E. 2005. "Refiguring Bodies", en M. Fraser y M. Greco (eds.), The Body. A Reader: 43-46. Nueva York-Oxford: Routledge. 
Hagedorn, J. M. (ed.). 2007. Gangs in the global city: alternatives to traditional criminology. Urbana: University of Illinois Press.

Hall, S. y T. Jefferson. (eds.) 2006 [1975]. Through Rituals. Youth Subcultures in Postwar Britain. Londres: Hutchinson.

Hollander, J. A. y R. L. Einwohner, 2004. "Conceptualizing Resistance". Sociological Forum 19 (4): 533-554.

Klein, M. 1995. The American Street Gang. Its Nature, Prevalence and Control. Nueva York: Oxford University Press.

Klein, M.; H. Kerner, et al. 2001. The Eurogang Paradox. Street Gangs and Youth Groups in the U.S and Europe. Dordrecht-Boston-Londres: Kluwer Academic Publishers.

Kontos, L.; D. Brotherton y L. Barrios. 2003. Gangs and Society. Alternative perspectives. Nueva York: Columbia University Press.

Mauss, M. 1971 [1950]. "Técnica y Movimientos corporales", en Sociología y Antropologia: 335-356. Madrid: Tecnos.

Merleau-Ponty, M. 2000. Fenomenología de la percepción. Barcelona: Península.

Porzio, L. 2009. Cos, biografia i cultures juvenils. Els estudis de cas dels skinheads $i$ dels Latin Kings \& Queens a Catalunya. DAFITS, Universitat Rovira i Virgili, Tarragona. Tesis Doctoral.

Porzio, L. y L. Giliberti. 2009. "Giovani, gruppi e pratiche culturali. Relazioni e conflitti nello spazio pubblico della periferia di Barcellona". Mondi Migranti. Rivista di studi e ricerche sulle migrazioni internazionali 2: 105-118.

Queirolo Palmas, L. 2008. "Etnografía de un mundo clandestino. Vida y política de la calle entre los jóvenes latinos en Italia", en M. Cerbino y L. Barrios, Otras naciones. Jóvenes, transnacionalismo y exclusión: 113-131. Quito: FLACSO.

Recio, C. y M. Cerbino. 2006. "Jóvenes 'latinos' y medios de comunicación”, en C. Feixa, L. Porzio y C. Recio. 2006. Jóvenes 'latinos' en Barcelona. Espacio público y cultura urbana: 165- 184. Barcelona: Anthropos.

Romaní, O.; L. Porzio; et al. 2009. "De Nacions, Reialeses i Marginacions. L'organització dels "Reyes y Reinas Latinos" de Catalunya. Un estudi de cas", Recerca i Immigració. Col-lecció Ciutadania i Immigració 4: 419-438.

Sayad, A. 2002 [1999]. La doppia assenza. Dalle illusioni dell'emigrato alle sofferenze dell'immigrato. Milán: Raffaello Cortina Editore.

Thornton, S. 1996 [1995]. Club Cultures. Music, Media and Subcultural Capital. Cambridge: Wesleyan University Press.

Trasher, F. 1963 [1926]. The Gang. A Study of 1313 Gangs in Chicago. Chicago: University Press.

Van Gemert, F.; D. Peterson y I. Lien. 2008. Street Gangs, Migration and Ethnicity. Devon: Willian Publishing.

Weitz, R. 2001. "Women and Their Hair: Seeking Power through Resistance and Accommodation." Gender and Society 15 (5): 667-686.

Fecha de recepción: 17 de noviembre de 2011

Fecha de aceptación: 8 de marzo de 2012 